\begin{tabular}{|l}
\hline FEB UNMUL \\
\hline
\end{tabular}

\title{
Pengaruh kebutuhan aktualisasi diri beban kerja dan kemampuan kerja terhadap prestasi kerja
}

\author{
Sheila Shintya Shasha ${ }^{1}$, Siti Maria ${ }^{2}$ \\ Fakultas Ekonomi dan Bisnis Universitas Mulawarman \\ ${ }^{1}$ Email: sheilashintya18@yahoo.com \\ ${ }^{2}$ Email: siti.maria@feb.unmul.ac.id
}

\begin{abstract}
Abstrak
Tujuan dari penelitian ini adalah untuk mengetahui besarnya pengaruh kebutuhan aktualisasi diri, beban kerja dan kemampuan kerja terhadap prestasi kerja. Penelitian ini dilakukan pada Balai Wilayah Sungai Kalimantan III Dinas PU Prov.Kaltim. Populasi dalam penelitian ini adalah sebanyak 61 orang. Penentuan sampel dengan menggunakan metode purpossive sampling. yaitu mengambil populasi pegawai tetap sebanyak 61 responden. Data dari penelitian ini menggunakan data primer yaitu kuesioner. Alat Analisis dalam penelitian ini menggunakan Regresi Liniear Berganda menggunakan SPSS versi 21 dan Uji hipotesis yang digunakan dalam penelitian ini adalah Uji $\mathrm{t}$ (Parsial).
\end{abstract}

Kata Kunci: kebutuhan aktualisasi diri; beban kerja; kemampuan kerja; prestasi kerja

\section{The effect of self-actualization needs on workload and work ability on work performance}

\begin{abstract}
The purpose of this study is to determine the magnitude of the effect of self-actualization needs, workload and work ability to work performance. This research was conducted at the River Region Hall Kalimantan III (Office PU Prov.Kaltim). The population in this study were 61 people. The determination of the sample by using purposive sampling method, which take the permanent employee population as much as 61 respondents. Data from this research use primary data that is kuesioner. The analytical tool in this research is using Multiple Linear Regression using SPSS version 21 and test of the hypothesis used in this research is $t$ Test (Partial). The results of this study indicate that : 1) Self-Actualization Needs a positive and significant impact on Work Perfomance in the River Region Hall Kalimantan III (Office of PU Prov.Kaltim). 2) Workload has a positive and significant impact on Work Performance in the River Region Hall Kalimantan III (Office of PU Prov.Kaltim). 3) Working Ability has a positive and significant effect on Work Performance in River Region Hall Kalimantan III (Office of PU Prov.Kaltim).
\end{abstract}

Keywords: self actualization needs; workload; work ability; work performance 


\section{PENDAHULUAN}

Setiap perusahaan atau instansi selalu berupaya agar pegawai yang terlibat dalam kegiatan perusahaan atau instansi dapat memberikan prestasi kerja setinggi mungkin untuk mewujudkan tujuan yang telah ditetapkan, maka pemeliharaan hubungan yang kontinyu dan serasi dengan para pegawai menjadi sangat penting. Salah satu hal yang penting diperhatikan dalam pemeliharaan hubungan tersebut adalah dengan penilaian prestasi kerja secara kontinyu. Prestasi kerja dapat diartikan sebagai hasil yang dicapai seseorang menurut ukuran yang berlaku untuk pekerjaan yang bersangkutan. setiap pegawai tetap dapat memberikan pertumbuhan dan perkembangan dalam pengembangan kapasitas diri sehingga dapat memotivasi seseorang pegawai tetap tersebut untuk menjadi yang terbaik dan dapat mengaktualisasikan dirinya sehingga dapat mempengaruhi prestasi kerjanya. Beban kerja baik itu beban kerja fisik atau beban kerja mental sangat penting bagi sebuah instansi. Dengan pemberian beban kerja yang efektif instansi tersebut dapat mengetahui sejauh mana pengaruhnya terhadap prestasi kerja itu sendiri. Kemampuan kerja pegawai tetap dalam melakukan suatu pekerjaan membuat pegawai tetap tersebut dapat memberikan kontribusi kepada instansinya secara maksimal, sehingga instansi tersebut memberikan penghargaan atas prestasinya selama ini, antara lain kenaikan jabatan.

\section{Tinjauan Pustaka}

\section{Kebutuhan Aktualisasi Diri}

Maslow dalam Adhani (2013:4), menemukan bahwa tanpa memandang suku asal-usul seseorang, setiap manusia mengalami tahap-tahap peningkatan kebutuhan atau pencapaian dalam kehidupannya. Kebutuhan tersebut meliputi kebutuhan fisiologis, kebutuhan keamanan dan keselamatan, kebutuhan sosial, kebutuhan akan penghargan, dan kebutuhan aktualisasi diri. Robbins dan Coulter dalam Azizah (2014:26), menyebutkan bahwa kebutuhan aktualisasi diri adalah kebutuhan seseorang untuk mampu menjadi apa yang diinginkan sesuai dengan potensi yang dimiliki.

\section{Beban Kerja}

Setiap individu melakukan aktivitas pekerjaan secara terus menerus setiap hari. Setiap pekerjaan yang dilakukannya merupakan beban yang harus ditanggung oleh pelakunya didalam melakukan pekerjaan tersebut sehingga disebut beban kerja. Pekerjaan yang dilakukan oleh seorang individu harus seimbang dengan kemampuan yang dimiliki oleh individu tersebut. Menurut Menpan dalam Dhania (2010:16), pengertian beban kerja adalah sekumpulan atau sejumlah kegiatan yang harus diselesaikan oleh suatu unit organisasi atau pemegang jabatan dalam jangka waktu tertentu.

\section{Kemampuan Kerja}

Robbins dan Judge dalam Dewi (2014:33), kemampuan berarti kapasitas seseorang individu untuk melakukan beragam tugas dalam suatu pekerjaan. lebih lanjut Robbin menyatakan bahwa kemampuan (ability) adalah sebuah penilaian terkini atas apa yang dapat dilakukan seseorang.

\section{Prestasi Kerja}

Organisasi adalah kumpulan orang yang memiliki kompetensi yang berbeda-beda, yang saling tergantung satu dengan yang lainnya, yang berusaha untuk mewujudkan kepentingan bersama mereka, dengan memanfaatkan berbagai sumber daya. Pada dasarnya tujuan bersama yang ingin diwujudkan oleh organisasi adalah mencari keuntungan. Oleh karena itu, diperlukan karyawan-karyawan yang mempunyai prestasi kerja yang tinggi. Menurut Sutrisno (2009:151), mengartikan prestasi kerja adalah sebagai hasil kerja yang telah dicapai seseorang dari tingkah laku kerjanya dalam melaksanakan aktivitas kerja.

\section{METODE}

\section{Definisi Operasional}

Definisi operasional adalah suatu definisi yang yang diberikan pada suatu variabel dengan memberi arti atau menspesifikasikan kegiatan atau membenarkan suatu operasional yang diperlukan untuk mengukur variabel tersebut.

\section{Variabel Independen (Independent Variable)}

Kebutuhan Aktualisasi Diri (X1) adalah suatu proses menjadi diri sendiri dengan mengembangkan sifat-sifat serta potensi individu untuk menjadi kepribadian yang utuh. Hal tersebut 
terlihat pada kegiatan pengembangan kapasitas diri melalui berbagai cara, seperti ikut pelatihan dan ikut acara sosialisasi atau seminar. Dengan indikator menurut Maslow dalam Azizah (2014:29), sebagai berikut:

\section{Persepsi yang tepat terhadap realita.}

Seseorang harus mampu memutuskan sesuatu secara benar dan jujur, menerima diri sendiri, orang lain, dan lingkungan dengan baik.

Seseorang harus mampu menerima lingkungan sosialnya beserta semua kekurangannya.

\section{Spontanitas.}

Seseorang sebaiknya memiliki spontanitas dan respon cepat terhadap segala sesuatu yang terjadi di sekitarnya.

\section{Kedekatan dengan individu yang lain.}

Untuk memenuhi tugas sebagai makhluk sosial, manusia harus membangun relasi yang baik dan berkesinambungan dengan sesamanya.

\section{Mendalami hubungan interpersonal.}

Hubungan interpersonal pada seseorang yang memiliki aktualisasi diri yang baik ditandai dengan hubungan timbal balik yang sangat mendalam dengan sesamanya.

Beban Kerja (X2) adalah sejumlah kegiatan yang harus diselesaikan oleh seseorang atau sekelompok pegawai dalam jangka waktu tertentu. Dengan indikator menurut Masclah dan Leither dalam Aprilia (2009:43), sebagai berikut:

\section{Bekerja terlalu intensif}

Bekerja keras secara intensif dapat meningkatkan hasil kerja yang baik, tetapi jika dilaksanakan secara terus menerus akan menimbulkan beban kerja yang berlebihan.

\section{Tuntutan pekerjaan yang berlebihan}

Banyaknya tuntutan pekerjaan yang harus diselesaikan secara cepat dapat menimbulkan kelelahan bagi para pekerja.

\section{Pekerjaan yang semakin kompleks}

Berbagai macam pekerjaan yang dihadapi mempunyai tingkat kesulitan tersendiri, maka semakin kompleks pekerjaan dapat menimbulkan beban pekerjaan yang berlebihan.

\section{Kelelahan yang berlebihan yang disebabkan oleh pekerjaan}

Kelelahan dapat mempengaruhi faktor emosi, kreatifitas, dan fisik yang dapat mengganggu kesehatan sehingga menyebabkan ketidakberdayaan dalam menghadapi pekerjaan.

Kemampuan Kerja (X3) adalah kecakapan atau kapasitas seseorang individu untuk melakukan atau mengerjakan beragam tugas dalam suatu pekerjaan baik secara mental ataupun fisik. berikut:

Dengan indikator menurut Sutermeister dan Bob Davis et.al dalam Riduwan (2005:45), sebagai

Menguasai keterampilan dasar

Memahami prosedur yang ditetapkan

Kreatif dalam bekerja

Melaksanakan tugas baru

Menguasai teknik operasional

Variabel Dependen (Dependent Variable)

Prestasi kerja adalah hasil kerja yang telah dicapai seseorang pegawai dalam melaksanakan aktivitas kerja selama periode tertentu.

Dengan indikator menurut Sutrisno (2009:152), sebagai berikut:

\section{Hasil kerja.}

Tingkat kuantitas maupun kualitas yang telah dihasilkan dan sejauh mana pengawasan dilakukan.

Pengetahuan pekerjaan.

Tingkat pengetahuan yang terkait dengan tugas pekerjaan yang akan berpengaruh langsung terhadap kuantitas dan kualitas dari hasil kerja. 


\section{Inisiatif}

Tingkat inisiatif selama melaksanakan tugas pekerjaan khususnya dalam hal penanganan masalah-masalah yang timbul.

\section{Kecekatan mental}

Tingkat kemampuan dan kecepatan dalam menerima instruksi kerja, dan menyesuaikan dengan cara kerja serta situasi kerja yang ada.

\section{Sikap}

Tingkat semangat kerja serta sikap positif dalam melaksanakan tugas pekerjaan.

Disiplin waktu dan absensi.

Tingkat ketepatan waktu dan tingkat kehadiran.

\section{Metode Pengumpulan Data}

Metode yang dilakukan dalam penelitian ini adalah untuk menjelaskan pengaruh antara variabel bebas/independent (kebutuhan aktualisasi diri, beban kerja dan kemampuan kerja) dan variabel terikat/dependent (prestasi kerja) dengan menggunakan metode survey terstruktur (kuesioner/angket) dengan pertanyaan tertutup. Kuesioner diisi oleh pegawai tetap yang bekerja di Balai Wilayah Sungai (Dinas PU Samarinda).

\section{Metode Analisis Data}

\section{Uji Instrumen}

\section{Uji Validitas}

Uji validitas digunakan untuk mengukur sah atau tidaknya suatu kuesioner. Suatu kuesioner dikatakan valid jika pada kuesioner mampu mengungkapkan sesuatu yang akan diukur oleh kuesioner tersebut. Pengujian validitas ini menggunakan Pearson Correlation yaitu dengan cara menghitung korelasi antara nilai yang diperoleh dari pertanyaan-pertanyaan. Suatu pertanyaan dikatakan valid jika tingkat signifikansinya berada di bawah 0,05. (Ghozali, 2012:52)

\section{Uji Reliabilitas}

Uji Reliabilitas sebenarnya adalah alat untuk mengukur suatu kuesioner yang merupakan indikator dari variabel konstruk. Suatu kuesioner dikatakan reliabel atau handal jika jawaban seseorang terhadap pertanyaan adalah konsisten atau stabil dari waktu ke waktu. Butir kuesioner dikatakan reliabel (layak) jika cronbach's alpha $>0,6$ dan dikatakan tidak reliabel jika cronbach's alpha < 0,6. (Ghozali, 2012:47)

\section{Analisis Regresi Liniear Berganda}

Analisis yang digunakan dalam penelitian ini menggunakan model regresi linier berganda dalam model ini yang diteliti terdiri dari dua variabel atau lebih, dimana dalam penganalisisan data variabel terdiri dari dua menjadi dua bagian yaitu variabel bebas (X) dan variabel terikat (Y). Menurut Setiaji (2008:23), analisa regresi dengan menggunakan persamaan sebagai berikut :

$$
\mathbf{Y}^{\prime}=\mathbf{a}+\mathbf{b}_{1} \mathbf{X}_{1}+\mathbf{b}_{2} \mathbf{X}_{2}+\mathbf{b}_{3} \mathbf{X}_{3}+\mathbf{e}
$$

Sumber: Setiaji (2008:23)

Keterangan :

$$
\begin{array}{ll}
\mathrm{Y}^{\prime} & =\text { Prestasi Kerja }(\mathrm{Y}) \\
\mathrm{a} & =\text { Konstanta } \\
\mathrm{X}_{1} & =\text { Kebutuhan Aktualisasi Diri }\left(\mathrm{X}_{1}\right) \\
\mathrm{X}_{2} & =\text { Beban Kerja }\left(\mathrm{X}_{2}\right) \\
\mathrm{X}_{3} & =\text { Kemampuan Kerja }\left(\mathrm{X}_{3}\right) \\
\mathrm{b}_{1} & =\text { Koefisien regresi untuk variabel Kebutuhan Aktualisasi Diri } \\
\mathrm{b}_{2} & =\text { Koefisien regresi untuk variabel Beban Kerja } \\
\mathrm{b}_{3} & =\text { Koefisien regresi untuk variabel Kemampuan Kerja } \\
\mathrm{e} & =\text { Kesalahan residu (error) }
\end{array}
$$

\section{Koefisien Korelasi (R)}

Koefisien korelasi digunakan untuk mengetahui pengaruh antara variabel independen (X) terhadap variabel dependen (Y). Perhitungan ini dinyatakan dengan rumus: 


$$
R=\frac{\sqrt{\mathrm{b} 1 \sum \mathrm{x} 1 \mathrm{y}+\mathrm{b} 2 \sum \mathrm{x} 2 \mathrm{y}+\mathrm{b} 3 \sum \mathrm{x} 3 \mathrm{y}}}{\sum \mathrm{y}^{2}}
$$

Menurut Sugiyono (2013:184), pedoman untuk memberikan interpretasi koefisien korelasi sebagai berikut :

Tabel 1. Interpretasi Koefisien Korelasi

\begin{tabular}{cc}
\hline Interval Koefisien & Tingkat Hubungan \\
\hline $0,00-0,199$ & Sangat rendah \\
$0,20-0,399$ & Rendah \\
$0,40-0,599$ & Sedang \\
$0,60-0,799$ & Kuat \\
$0,80-1,000$ & Sangat Kuat \\
\hline
\end{tabular}

Sumber : Sugiyono, 2013:184

\section{Koefisien Determinasi $\boldsymbol{R}^{2}$}

Menurut Ghozali (2012:97), koefisien determinasi $\left(\mathrm{R}^{2}\right)$ merupakan alat untuk mengukur seberapa jauh kemampuan model dalam menerangkan variasi variabel dependen. Nilai koefisien determinasi adalah antara nol atau satu. Nilai $\left(\mathrm{R}^{2}\right)$ yang kecil berarti kemampuan variabel-variabel independen dalam menjelaskan variasi variabel dependen amat terbatas. Dan sebaliknya jika nilai yang mendekati 1 berarti variabel-variabel independen memberikan hampir semua informasi yang dibutuhkan untuk memprediksi variabel-variabel dependen.

\section{Pengujian Hipotesis}

\section{Uji Parsial (Uji t)}

Menurut Ghozali (2012:98), Uji beda t-test digunakan untuk menguji seberapa jauh pengaruh variabel independen yang digunakan dalam penelitian ini secara individual dalam menerangkan variabel dependen secara parsial. Dasar pengambilan keputusan digunakan dalam uji t adalah sebagai berikut:

\section{Berdasarkan nilai $t$ hitung dan $t$ tabel:}

Jika nilai $\mathrm{t}$ hitung $>\mathrm{t}$ tabel maka $\mathrm{H} 0$ ditolak dan $\mathrm{H} 1$ diterima yang berarti variabel bebas berpengaruh terhadap variabel terikat.

Jika nilai $\mathrm{t}$ hitung $<\mathrm{t}$ tabel maka H0 diterima dan $\mathrm{H} 1$ ditolak yang berarti variabel bebas tidak berpengaruh terhadap variabel terikat.

\section{Berdasarkan nilai signifikansi hasil output SPSS:}

Jika nilai probabilitas signifikansi $<0,05$, mempunyai arti bahwa variabel independen berpengaruh signifkan terhadap variabel dependen.

Jika nilai probabilitas signifikansi > 0,05, mempunyai arti bahwa variabel independen tidak berpengaruh signifkan terhadap variabel dependen.

\section{HASIL DAN PEMBAHASAN}

\section{Hasil Uji Instrumen}

Tabel 2. Uji Validitas

\begin{tabular}{lccc}
\hline \multicolumn{1}{c}{ Indikator } & Nilai korelasi & r tabel & Keterangan \\
\hline Persepsi yang tepat terhadap realita & 0,845 & 0,266 & \\
Menerima diri sendiri, orang lain dll & 0,844 & 0,266 & \\
Spontanitas & 0,826 & 0,266 & \\
Kedekatan dengan Individu yang lain & 0,876 & 0,266 & \multirow{2}{*}{ Valid } \\
Mendalami hubungan interpersonal & 0,883 & 0,266 & \\
Bekerja terlalu intensif & 0,841 & 0,266 & \\
Tuntutan pekerjaan yang berlebihan & 0,838 & 0,266 & \\
Pekerjaan yang semakin kompleks & 0,846 & 0,266 & \\
& & &
\end{tabular}




\begin{tabular}{lll}
\hline Kelelahan yang berlebihan & 0,829 & 0,266 \\
\hline Menguasai keterampilan dasar & 0,806 & 0,266 \\
Memahami prosedur yang ditetapkan & 0,795 & 0,266 \\
Kreatif dalam bekerja & 0,776 & 0,266 \\
Melaksanakan tugas baru & 0,883 & 0,266 \\
Menguasai teknik operasional & 0,787 & 0,266 \\
Hasil kerja & 0,745 & 0,266 \\
Pengetahuan pekerjaan & 0,797 & 0,266 \\
Inisiatif & 0,783 & 0,266 \\
Kecekatan mental & 0,785 & 0,266 \\
Sikap & 0,783 & 0,266 \\
Disiplin waktu dan absensi & 0,776 & 0,266 \\
\hline
\end{tabular}

Sumber: Data primer diolah, 2017

Hasil pengujian validitas pada semua variabel bahwa masing-masing indikator variabel mempunyai nilai korelasi lebih besar dari $r$ tabel $(0,266)$ sehingga semua pertanyaan dalam kuesioner dinyatakan valid.

\section{Uji Reliabilitas}

Tabel 3. Uji Reliabilitas

\begin{tabular}{clccc}
\hline No. & \multicolumn{1}{c}{ Variabel } & Cronbach's Alpha & Kriteria & Status \\
\hline 1. & Prestasi Kerja Pegawai $(\mathrm{Y})$ & 0.864 & \multirow{2}{*}{ Cronbach Alpha } & Reliabel \\
2. & Kebutuhan Aktualisasi Diri $\left(\mathrm{X}_{1}\right)$ & 0.905 & $>0,6$ & Reliabel \\
3. & Beban Kerja $\left(\mathrm{X}_{2}\right)$ & 0.859 & Maka reliabel & Reliabel \\
4 & Kemampuan Kerja $\left(\mathrm{X}_{3}\right)$ & 0.867 & & Reliabel \\
\hline
\end{tabular}

Sumber: Data primer diolah, 2017

Berdasarkan tabel 4.2 diatas uji reliabilitas dilakukan terhadap item pertanyaan yang dinyatakan reliabel. Kriteria suatu instrument dikatakan reliabel dengan menggunakan teknik ini, bila Cronbach alpha > 0,6 namun sebaliknya apabila Cronbach alpha $<0,6$ hal ini menunjukkan tidak adanya konsistensi.

\section{Analisis Regresi Linear Berganda}

Nilai koefisien variabel bebas atau nilai beta dari masing-masing variabel yang mempengaruhi prestasi kerja berturut-turut adalah sebagai berikut: konstanta sebesar 0,487 , kebutuhan aktualisasi diri $\left(X_{1}\right)$ sebesar 0,361, beban kerja $\left(X_{2}\right)$ sebesar 0,297 dan kemampuan kerja $\left(X_{3}\right)$ sebesar 0,262.

Tabel 4. Uji t

Coefficients $^{\mathrm{a}}$

\begin{tabular}{|c|c|c|c|c|c|c|}
\hline \multirow{2}{*}{\multicolumn{2}{|c|}{ Model }} & \multicolumn{2}{|c|}{$\begin{array}{c}\text { Unstandardized } \\
\text { Coefficients }\end{array}$} & \multirow{2}{*}{$\begin{array}{c}\text { Standardized } \\
\text { Coefficients } \\
\text { Beta }\end{array}$} & \multirow[t]{2}{*}{$\mathrm{t}$} & \multirow[t]{2}{*}{ Sig. } \\
\hline & & B & Std. Error & & & \\
\hline \multirow{4}{*}{1} & (Constant) & .487 & .207 & & 2.353 & .022 \\
\hline & $\begin{array}{l}\text { Kebutuhan Aktualisasi } \\
\text { Diri }\end{array}$ & .361 & .079 & .380 & 4.536 & .000 \\
\hline & Beban Kerja & 297 & .087 & .340 & 3.397 & .001 \\
\hline & Kemampuan Kerja & .262 & .088 & .280 & 2.983 & .004 \\
\hline
\end{tabular}

a. Dependent Variable: Prestasi Kerja Pegawai

Sumber: Data Hasil Penelitian SPSS 21

Sehingga model persamaan regresi dapat ditulis sebagai berikut :

$$
\begin{aligned}
& \mathbf{Y}=\mathbf{a}+\mathbf{b}_{1} \mathbf{X}_{1}+\mathbf{b}_{2} \mathbf{X}_{2}+\mathbf{b}_{3} \mathbf{X}_{\mathbf{3}}+\mathbf{e} \\
& Y=0,487+0,361 \mathbf{X}_{1}+0,297 \mathrm{X}_{2}+0,262 \mathrm{X}_{3}+0,163
\end{aligned}
$$




\section{Interpretasi dari model :}

Nilai konstanta 0,487 menunjukkan bahwa bila nilai variabel kebutuhan aktualisasi diri $\left(\mathrm{X}_{1}\right)$, beban kerja $\left(\mathrm{X}_{2}\right)$ dan kemampuan kerja $\left(\mathrm{X}_{3}\right)$ tanpa mengalami perubahan atau tetap maka variabel prestasi kerja pegawai di Balai Wilayah Sungai Kalimantan III (Dinas PU Prov.Kaltim) akan mengalami peningkatan yaitu sebesar 0,487.

Jika ada penambahan satu satuan variabel kebutuhan aktualisasi diri terhadap variabel prestasi kerja pegawai di Balai Wilayah Sungai Kalimantan III (Dinas PU Prov.Kaltim) maka akan mengalami peningkatan sebesar 0,361

Jika ada penambahan satu satuan variabel beban kerja terhadap variabel prestasi kerja pegawai di Balai Wilayah Sungai Kalimantan III (Dinas PU Prov.Kaltim) maka akan mengalami peningkatan sebesar 0,297

Jika ada penambahan satu satuan variabel kemampuan kerja terhadap variabel prestasi kerja pegawai di Balai Wilayah Sungai Kalimantan III (Dinas PU Prov.Kaltim) maka akan mengalami peningkatan sebesar 0,262

\section{Koefisien Korelasi (R)}

Tabel 5. Koefisien Korelasi dan Determinasi Model Summary

\begin{tabular}{llrrr}
\hline Model & R & R Square & Adjusted R Square & Std. Error of the Estimate \\
\hline 1 & $.915^{\mathrm{a}}$ & .837 & .828 & .21122 \\
\hline
\end{tabular}

a. Predictors: (Constant), Kemampuan Kerja, Kebutuhan Aktualisasi Diri, Beban Kerja

Sumber: Data primer diolah dengan SPSS 21

Berdasarkan tabel di atas terlihat bahwa besarnya nilai R (korelasi) atau tingkat hubungan antar variabel adalah sebesar 0,915 atau sebesar 91,50\%. Artinya variabel kebutuhan aktualisasi diri, beban kerja dan kemampuan kerja secara keseluruhan mempunyai korelasi yang sangat kuat dengan prestasi kerja pegawai di Balai Wilayah Sungai Kalimantan III (Dinas PU Prov.Kaltim).

\section{Koefisien Determinasi $\left(\mathbf{R}^{\mathbf{2}}\right)$}

Sedangkan besar angka $\mathrm{R}$ square $\left(\mathrm{R}^{2}\right)$ atau tingkat pengaruh antar variabel adalah sebesar 0,837 atau sebesar $83,70 \%$. Angka ini mempunyai maksud bahwa pengaruh dari variabel kebutuhan aktualisasi diri, beban kerja dan kemampuan kerja secara keseluruhan terhadap prestasi kerja pegawai di Balai Wilayah Sungai Kalimantan III (Dinas PU Prov.Kaltim) adalah sebesar 83,70\% sedangkan sisanya $16,30 \%$ dipengaruhi oleh faktor lain.

\section{Pengujian Hipotesis}

\section{Uji Parsial (Uji t)}

Kebutuhan Aktualisasi Diri (X1) terhadap Prestasi Kerja Pegawai (Y) pada Balai Wilayah Sungai Kalimantan III (Dinas PU Prov.Kaltim)

Berdasarkan hasil analisis diperoleh nilai Sig $(0,000)<\alpha(0.05)$ dan nilai thitung $=4,536>$ ttabel $=2,001$, maka secara parsial berpengaruh signifikan serta diputuskan menolak H0 dan menerima Ha.

Beban Kerja (X2) terhadap Prestasi Kerja Pegawai (Y) pada Balai Wilayah Sungai Kalimantan III (Dinas PU Prov.Kaltim)

Berdasarkan hasil analisis diperoleh nilai Sig $(0,001)<\alpha(0.05)$ dan nilai thitung $=3,397>$ ttabel $=2,001$, maka secara parsial berpengaruh signifikan serta diputuskan menolak H0 dan menerima Ha.

Kemampuan Kerja (X3) terhadap Prestasi Kerja Pegawai (Y) pada Balai Wilayah Sungai Kalimantan III (Dinas PU Prov.Kaltim)

Berdasarkan hasil analisis diperoleh nilai Sig $(0,004)<\alpha(0.05)$ dan nilai thitung $=2,983>$ ttabel $=2,001$, maka secara parsial berpengaruh signifikan serta diputuskan menolak $\mathrm{H} 0$ dan menerima Ha.

\section{Kebutuhan Aktualisasi Diri (X1) terhadap Prestasi Kerja (Y)}

Ada pengaruh positif dan signifikan variabel kebutuhan aktualisasi diri terhadap variabel prestasi kerja pegawai di Balai Wilayah Sungai Kalimantan III (Dinas PU Prov.Kaltim). Hal ini didukung oleh penelitian yang dilakukan oleh Adhani (2013), yang menyimpulkan bahwa karyawan yang dapat mengaktualisasikan diri ditempat kerja dapat meningkatkan prestasi kerjanya. 


\section{Beban Kerja (X2) terhadap Prestasi Kerja (Y)}

Ada pengaruh signifikan variabel beban kerja terhadap variabel prestasi kerja pegawai di Balai Wilayah Sungai Kalimantan III (Dinas PU Prov.Kaltim). Hal ini didukung penelitian yang dilakukan oleh Mudayana dalam Adhani (2013:8-9) yang menyatakan bahwa karyawan akan tetap bekerja dengan baik meskipun beban kerja yang diterima tinggi atau sedang, selama mereka masih termotivasi dalam bekerja.

\section{Kemampuan Kerja (X3) terhadap Prestasi Kerja (Y)}

Ada pengaruh signifikan variabel kemampuan kerja terhadap variabel prestasi kerja pegawai di Balai Wilayah Sungai Kalimantan III (Dinas PU Prov.Kaltim). Robbins dalam Perdana (2012:32), mengemukakan bahwa tingkat kinerja/prestasi pegawai akan sangat bergantung pada faktor kemampuan pegawai itu sendiri seperti tingkat pendidikan, pengetahuan, pengalaman dimana dengan tingkat kemampuan yang tinggi akan mempunyai kinerja/prestasi yang tinggi pula.

\section{SIMPULAN}

Berdasarkan hasil perhitungan, analisis dan pembahasan maka, berikut ini akan dikemukakan beberapa kesimpulan:

Kebutuhan aktualisasi diri berpengaruh positif dan signifikan terhadap prestasi kerja pegawai di Balai Wilayah Sungai Kalimantan III (Dinas PU Prov.Kaltim). Hal ini berarti kebutuhan aktualisasi dirinya tersebut maka akan memberikan prestasi kerja yang baik di instansinya.

Beban kerja berpengaruh positif dan signifikan terhadap prestasi kerja pegawai di Balai Wilayah Sungai Kalimantan III (Dinas PU Prov.Kaltim). beban kerja yang tinggi tersebut justru mereka bisa terus meningkatkan prestasi kerja mereka.

Kemampuan kerja berpengaruh positif dan signifikan terhadap prestasi kerja pegawai di Balai Wilayah Sungai Kalimantan III (Dinas PU Prov.Kaltim). kemampuan tinggi mereka dapat mempengaruhi prestasi kerja di instansinya.

\section{DAFTAR PUSTAKA}

Adhani, A. R. 2013. Pengaruh Kebutuhan Aktualisasi Diri dan Beban Kerja terhadap Prestasi Kerja Karyawan PT. Bank Tabungan Negara Kantor Cabang Syariah Surabaya, Jurnal Ilmu Manajemen, 1(4), 1223-1233, Universitas Negeri, Surabaya.

Aprilia, Esti. 2009. Stres Kerja Pada Medical Representatif Di PT Daria Varia Ditinjau Dari Beban Kerja, Skripsi, Fakultas Psikologi, Universitas Katolik Soegijapranata, Semarang.

Azizah, Dianingtyas. 2014. Pengaruh Penghargaan dan Kebutuhan Aktualisasi Diri terhadap Prestasi Kerja Karyawan pada PT. Telkom Kotabaru Yogyakarta, Skripsi, Universitas Negeri, Yogyakarta.

Dewi, Nurul Rohana. 2014. Pengaruh Kemampuan, Motivasi dan Lingkungan Kerja terhadap Kinerja Karyawan (Studi Pada BMT Taruna Sejahtera), Skripsi, Sekolah Tinggi Agama Islam Negeri, Salatiga.

Dhania, D.R. 2010. Pengaruh Stress, Beban Kerja Terhadap Kepuasan Kerja (Studi Pada Medical Representatif Di Kota Kudus), Jurnal Psikologi, Universitas Muria, Kudus, Volume, No 1, Desember 2010.

Ghozali, Imam. 2012. Aplikasi Analisis Multivariate dengan Program IBM SPSS 20, UNDIP, Semarang.

Perdana. Mukzam. dan Nurtjahjono. 2013. Pengaruh Motivasi dan Kemampuan Kerja terhadap Prestasi Kerja Karyawan (Studi pada Karyawan PT. Bank Tabungan Negara, Tbk. Cabang Surabaya), Jurnal Ilmu Administrasi, Universitas Brawijaya, Malang.

Riduwan. 2005. Skala Pengukuran Variabel-Variabel Penelitian, Alfabeta, Bandung.

Riduwan. 2007. Pengantar Statistika untuk Penelitian Pendidikan Sosial-Ekonomi dan Bisnis, CV Alfabeta, Bandung. 